\title{
MODELO DE UM SISTEMA EUTRÓFICO: FLUXO DOS NUTRIENTES E SINECOLOGIA DAS POPULAÇÕES PLANCTONICAS
}

\author{
PATRICIA BENON, FRANÇOIS BLANC, BRIGITTE BOURGADE, \\ PIERRE KERAMBRUN, MICHEL LEVEAU, PASCAL DAVID \\ Centre Universitaire de Marseille-Luminy, F rança
}

JEAN CLAUDE ROMANO, DOMINIQUE SAUTRIOT

Station Marine d'Endoume. Marseille, França

ROGER KANTIN

Base Oceanográfica Atlântica, Rio Grande, RS, Brasil

\section{SYNOPSIS}

Based on the information obtained from the Gulf of Fos, France, we propose herewith a generalized model to characterize the physical, chemical and biological parameters and their interrelationship in the eutrophic coastal system. This system is characterized by having high concentration of suspended materials, especially the mineral fraction $(C / N>30)$. Nutrients concentrations are very high, except in diluted basins. The N-NO3/P-P04 ratio is usually low, due to the preferential assimilation of nitrates and the presence of polyphosphates from sewage waters. The concentrations of phaeopigments are always high (more than 50\%), due to the mortalities of freshwater originated phytoplankton, the resuspension of dead vegetal materials, and the grazing of zooplankton. We noted in diluted water of eutrophic system the biomass is high, but the diversity is relatived low, among adapted cells with low "energetic charge". Whereas in oceanic water, the biomass is less, the diversity and energetic charge are increasing. Ihis may indicate that phytoplankton communuties have to make an effort to grow and duplicate. In comparing zooplankton populations from eutrophic to oligotrophic waters, biochemical diferentiations were observed for a same species, which may due to the difference in salinities and the presence of chemical pollutants.

Introduçẫo

As zonas eutróficas são hoje em dia, objeto de vários estudos, seja num interesse puramente científico, seja num interesse haliêutico. Muito ricas em fito e zooplâncton, essas zonas são, muitas vezes, áreas de reprodução dos peixes.

A eutrofização consiste em um aumento natural ou artificial das concentrações em sais nutrientes e as conseqüências deste enriquecimento. ( Blanc \& Leveau, 1973). E um fenômeno natural muito lento, podendo 'ser acelerado pela aç̧̃o humana. Esta eutrofizaçăo artificial não controlada, conduz a uma modificação da composição específica das populações. algais, com uma preponderância de algumas espécies, as vezes indesejáveis, que se desenvolvem ativamente e cuja enorme biomassa pode conduzir a uma poluição do tipo "biológico".

Uma distinção deve então ser feita, entre a eutrof zzaçấo "sensu stricto", quer dizer, a superfertilização propriamenté dita, e as suas consequiências, que pódem revestir-se de diversas formas.

De um modo geral, os principais sais nutrientes responsaveis pela eutrofizaçđo são os nitratos e os fosfatos; mas outros agentes podem intervir como fatores limitantes (silicatos, $\mathrm{C} 02$, ou alguns oligo-elementos). Esses componentes, em quantidade relativamente elevada nos rios, provacam ao chegar no mar, um enriquecimento mais ou menos importante dessas zonas estuanais.

Quanto as ongens artificiais, elas podem ter diversas origens: agrícola, industrial ou doméstica.

As condições geográficas e climáticas, intervêm igualmente nos processos eutrofizantes, bem como a abundância e a particularidade local da flora e da fauna marinha, pelágica ou bentônica.

As repercussões da eutrofização sobre ecossistemas marinhos, são consideráveis. Traduzem-se por mudanças na abundância e na diversidade das populaçōes presentes, e por uma diminuição da estrutura do ecossistema. Nos casos extremos, uma espécie única desenvolve-se desmedidamente, "explodida" em detrimento dos seus parceiros ecológicos.

Consideraremos aqui, somente os aspectos ligados à estrutura hidrológica, e às suas repercussões sobre as populaçб̃es planctônicas: resultados parciais já foram publicados sobre esse assunto especialmente no que diz respeito ao estudo da repartição dos principais parâmetros físico-químicos e biológicos em zona eutrófica (Benon et al., 1975a; Benon et al., 1975b; Benon et al., 1977; Blanc \& Leveau., 1970a; Blanc \& Leveau 1970b; Blanc et al., 1973; Blanc et al., 1975a; Blanc et al., 1975b; Blanc et al., 1976; David et al., 1977).

Consideraremos como referência, os trabalhos efetuados no "Golfo de Fos" (França), na saída do Ródano que, com um débito anual médio de $1.800 \mathrm{~m}^{3} / \mathrm{s}$ é o rio mais importante do Mediterrâneo Norte-Ocidental. A partir desses resultados, uma generalização será feita para dar as grandes linhas que regem a hidrobiologia dos sistemas estuariais.

\section{Estrutura Hidrológica}

A intrusão fluvial no meio marinho, modificando as características físico-químicas da água do mar, provoca profundas modificaçōes na biologia das populaçð̄es planctônicas. Essas são engendradas, não somente pela baixa salinidade e as variaçōes térmicas, e portanto pelas mudanças de densidade e viscosidade das águas que condicionam a flutuabilidade dos organismos planctônicos, mas também pelas contribuições maciças de sais nutrientes, de matéria orgânica e eventualmente, de substâncias tóxicas (poluentes). Isso se traduz sobretudo pelas alterações na estrutura e na dinâmica das suas populaçoes, sua diversidade, sua biomassa, seu metabolismo, sua fisiologia, etc. Nessas zonas, a produção primária e secundária são extremamente elevadas, em detrimento da diversidade específica que diminui.

Por outro lado, a extensão das camadas de diluição sofre no decurso do ano, grandes variações seguindo as estações, as precipitações, a direção, a força e a duração dos ventos. As marés e as correntes, desempenham igualmente, um papel não negligenciável na sua extenșão. Deve-se assinalar, enfim. a forca de Coriolis. devido à rotação da Terra, que para o Ródano, tem tendência a desviar a camada de diluição na direção oeste.

A carga de material particulado em suspensão é, nessas zonas, muito elevada: os teores em material orgânico são mais ou menos 10 vezes superiores aos das áreas neríticas puras. Podemos, assim, notar no Golfo de Fos, teores em material particulado superiores a $5 \mathrm{mg} / \ell$, os mais altos tendo sido encontrados na própria saída do rio $(130 \mathrm{mg} / \ell)$. O estudo da relação carbono/nitrogênio do material particulado permite estimar a parte tomada pelo carbono mineral no carbono total. As relações muito elevadas obtidas no estuário de Ródano, onde as razões $\mathrm{C} / \mathrm{N}$ eram superiores a 30 , mostram a parte importante tomada pelo carbono mineral. Com efeito, na matéria orgânica viva, as relaçōes $\mathrm{C} / \mathrm{N}$ são de 4 a 8 . Tais valores encontram-se entretanto, numa certa distância das emergências e igualmente embaixo da camada de diluição nas águas marinhas de fraca turbidez. Nas zonas de baixa profundidade, onde a penetração das águas é limitada, os rendimentos são muito mais elevados. Esta riqueza em material orgânico tem por origem a presença de vários restos de vegetais superiores e de cadáver de animais. Além disso, o alto nível de prođutividade primaria e secundária, concorre para o aumento destes teores, já muito elevados.

As concentrações de oxigênio dissolvido, notadas nas áreas de baixa salinidade, são muito variáveis; elas são essencialmente a conseqüência dos processos de fotossíntese e da ação dos ventos, havendo tendência a aumentar os teores nas camadas superficiais, bem como dos processos de biodegradação, concorrendo para reduzir os teores em oxigênio dissolvido nas águas de superfície. Qs teores mais altos foram encontrados na própria saída do Ródano $(7,5 \mathrm{ml} / \mathrm{l})$. Teores ainda importantes $(6,5 \mathrm{~m} / / \bar{\ell})$, foram igualmente encontrados a $5 \mathrm{~m} \cdot$ de profundidade. Em compensação, nas águas tipicamente marinhas, onde a produção primária é menor, as concentracões de oxigênio dissolvido são mais baixas (entre 5,5 e $5,9 \mathrm{~m} \ell / \ell)$. 


\section{A Reserva Nutritiva}

Nas áreas de diluição, a reserva nutritiva é intensa; provém não somente das contribuições efetuadas pelos rios, mas igualmente de vários restos arrancados do fundo pelas correntes e contra correntes.

Segundo a maioria dos autores. são essencialmente os fosfatos que provocam os processos eutrofizantes nas águas doces (Lund, 1969; Provasoli, 1969) ou marinhas '(Carpenter et al., 1969, Berland et al., 1974). Além disso, o "turn over" muito rápido do nitrogênio, e numa medida menor, a presença de organismos zooplanctônicos, regenerando uma parte dos sais nutrientes, podem concorrer para a conservação de uma certa eutrofizaçăo. Os fosfatos constituem com efeito, o elemento principal rejéitado por eles (Pomeroy et al., 1963; Hargane \& Queen, 1968; Peters, 1975). Uma certa parte pode ser também, liberada depois de sua morte (Seiwell \& Seiwell, 1938. Assim, elevados teores em fosfatos (1.70 $\mu$ atg/ $($ ) foram encontrados a $5 \mathrm{~m}$ de profundidade, onde eram presentes, altas concentraçōes zooplanctônicas (mais de 10.000 organismos/litro). As substâncias nitrogenadas, trazidas pelas águas de origem continental, desempenham igualmente, um papel importante no desenvolvimento do nível primário. Em algumas zonas eutróficas, como o Golfo de Fos, o nitrogênio não constitui um fator limitante, pois os teores de nitratos são muito elevados e as outras formas do nitrogênio são abundantes. Porém, segundo a riqueza de organismos fitoplanctônicos dessas zonas e segundo as estaçð̃es, os teores em nitratos podem diminuir consideravelmente os processos de assimilação pelos produtores primários, sendo preponderantes em relação às chegadas das águas continentais Nessas zonas, entretanto, o "turn over" do nitrogênio é rápido, e as baixas concentrações em nitratos encontrados, não prejudicam o desenvolvimento fitoplanctônico, cuja biomassa é particularmente elevada. Além disso, alguns organismos fitoplanctônicos podem assimilar, sob condições particulares, o amônio, os nitritos (Carlucci et al., 1970), a uréia (McCarthy, 1972) e mesmo as substâncias nitrogenadas dissolvidas, como os ácidos aminados (Bruce, 1969). Alguns deles, capazes de heterotrofia, poderiam mesmo, assimilar a matéria carbonada dissolvida (Sloan \& Strickland, 1966).

A relação NO3/P-PO4, nas áreas eutróficas, é geralmente bai$\mathrm{xa}$, sobretudo nas zonas onde o nível primário é importante. Os baixos valores dessa relação são ocasionados, no Golfo de Fos, para uma pequena parte por um consumo preferencial mais rápido e mais importante dos nitratos, pelas células foto-autotróficas, sobretudo pelas rejeições de fosfatos, de origem agrícola (criação), doméstica (rejeições humanas e rejeições de polifosfatos associados aos detergentes), bem como industriais.

0 Golfo de Fos, é, com efeito, a sede de rejeiçōes urbanas e industriais importantes; essas rejeiçōes, ricas em fosfatos, contribuem para diminuir a relação N-NO3/P-PO4. Porém, nas zonas situadas imediatamente na própria saída dos rios, as relações N-NO3/P-PO4, são mais elevadas apesar das fortes densidades fitoplanctônicas (N/P 20, na saída do Ródano, em superfície); nessas zonas, as células fitoplanctônicas não têm tempo de utilizar a importante reserva nutritiva que está a sua disposição, e os teores em nutrientes ficam elevados. A assimilação dos nitratos pelo nível primário, é bem mais marcado, quando as densidades algais são elevadas, e quando o tempo de permanência dos organismos fitoplanctônicos nas águas é prolongado.

Ao contrário, algumas áreas em comunicação com o mar (lagoas e lagos), são amplas bacias de diluição, onde os organismo fitoplanctónicos têm tempo de assimilar a reserva nutritiva a sua disposição. Quando essas águas de baixa salinidade entram em contáto com as águas marinhas, a reserva nutritiva é parcialmente (ou totalmente) utilizada.

E precis̄o assinalar, que um desequilíbrio demasiado grande da relação N/P (inferior a 1), é desfavorável aos organismos fitoplanctônicos. Com efeito, este desequilíbrio modifica a composição específica das populaçð̄es permitindo somente o desenvolvimento de um número limitado de espécies algais, podendo em alguns casos, formar "águas descoloridas". Um tal fenômeno foi observado por Ryther (1954) num estuário de Long Island (USA), Nitzschia closterium, espécie comum desse estuário, que estava excluída desse meio em consequiência de rejeições de efluentes de criação em proveito de duas pequenas algas verdes, atingindo a concentração de 100 milhões de células por litro; elas desenvolviam-se duas vezes mais rapidamente nas águas, onde a relação $\mathrm{N} / \mathrm{P}$ aproxima-se de 5. Quanto aos silicatos que entram na composiçã̃o da carapaça das diatomáceas, nunca são um fator limitante, mesmo quando as densidades celulares forem muito elevadas (Benon et al., 1977).

\section{Sinecologia das Comunidades Fitoplanctonicas}

As populaçoes fitoplanctônicas, desenvolvendo-se nas áreas de diluição, abundante em número e biomassa, caracterizam-se por uma pouca especificidade das listas taxonômicas e logo, por um fraco indício de diversidade, traduzindo a imaturidade das populações fitoplanctônicas e a fraca adaptação da maior parte delas. Com efeito, a maior parte das espécies de zonas neríticas, não podem adaptar-se às novas condiçőes do meio; somente algumas espécies podem sobreviver e, desenvolvem-se então, de maneira bem mais exuberante, quando a carga nutritiva for elevada. As populaçōes fitoplanctônicas, nessas zonas são constituídas de espécies de tamanho muito pequeno, de potencial multiplicativo elevado, possuindo uma relação de superfície/volume elevado (tal Skeletonema costatum, que permite-thes uma melhor assimilação dos sais nutrientes). $O$ desaparecimento da maior parte das espécies eurihalinas, é representado por uma diminuição do indício de diversidade.

Dentro das espécies de água doce, suportando uma salinidade realativamente elevada, podem ser citadas, as diatomáceas dos gêneros, Melosira e Cyclotella, bem como as clorofíceas scenedesmiais, e diversos nanoflagelados. Reparamos igualmente, no decurso de nossos levantamentos, a presença de dinoflagelados e sobretudo da Prorocentridae. Esses organismos heterótrofos facultativos podem, em algumas condições, multiplicar-se de uma maneira intensa, especialmente nas zonas afetadas por uma polui ção urbana, e excretar compostos metabólicos tóxicos, excluindo as outras espécies animais ou vegetais (fenômeno de "aguas descoloridas" precedentemente mencionado). Por fim, a proliferação das cianofíceas, nas águas doces eutróficas, é bem conhecido; al gumas espécies do gênero Oscillatoria foram coletadas em todas as áreas de diluição consideradas. A sua importância não é negligenciável, pois algumas cianofíceas, associadas à bactérias, são capazes de fixar diretamente o nitrogênio atmosférico (Sournia, 1970) aumentando ainda mais a biomassa fitoplanctônica

Segundo as disponibilidades das reservas nutritivas e o estado da poluição, observa-se espécies dulciaquícolas de estado 1 ou 2 , Senso de Margalef, mas igualmente cianofíceas (estado 3 ), bem como ciliados e alguns organismos zooplanctônicos em menor quantidade.

No nível da chegada de agua doce no mar, a maior parte dos organismos fitoplanctônicos de origem dulciaquícola não podem adaptar-se às bruscas variações termohalinas do meio ambiente. Resulta uma mortandade macica, traduzindo-se por teores em feopigmentos muito elevados $(2 \mu \mathrm{g} / \mathrm{l})$, podendo representar ate $50 \%$ dos pigmentos totais (David et al., 1977). Os feopigmentos, pigmentos de degradação da clorofila, provém em grande parte de células de origem dulciaquícola, mortas em conseqüência do "stress" halino, ou de células mortas e sedimentadas sobre fundos pouco profundos, recolocadas em suspensão pela agitação do mar. A observação da composição específica zooplanctônica permite ver, além disso, uma boa relação entre os teores em feofitinas e a densidade do cladócero Podon polyphemoides (Benon et al., 1977), consideradas por Lorenzen (1967) como um indício de "pressão" de grazing.

A representatividade da parte fitoplanctônica viva, é mass retidamente definida pelos teores em adenilatos do fitoplâncton e mais particularmente, em ATP e em ADP. Com efeito, ainda que pigmentos clorofilados utilizem várias horas para degradar-se, a transformação do ATP demanda somente alguns minutos. As zonas de estuário, de salininidade média $(30$ a $35 \%)$ e de alta turbidez, têm concentrações elevadas para todos os fatores de biomassa. Os teores em adenilatos encontrados nas zonas de diluição do Golfo de Fos são assim, particularmente elevados ( $565 \mathrm{pm} / 1$ para ATP e ADP e $427 \mathrm{pm} / 1$ para o AMP). Segundo Bomsel \& Pradet (1967) chamamos "carga energética" a relação $\mathrm{CE}: \mathrm{CE}=\begin{gathered}\mathrm{ATP}+1 / 2 \mathrm{ADP} \\ \mathrm{ATP}+\mathrm{ADP}+\mathrm{AMP}\end{gathered}$ que permite dar uma imagem estado metabólico das células (Bomsel \& Pradet, 1967; Pradet et al., 1968; Romano, 1975. A distribuição da carga energética segue de muito perto aquelas das densidades fitoplanctônicas; constata-se que as zonas onde a carga energética é fraca, superpõem-se aquelas apresentando os mais altos valores em ATP, ADP e $\Sigma(\Sigma=$ ATP + ADP + AMP), logo, os mais ricos em biomassa. Ao contrário, nas zonas neríticas oligotróficas, a carga energética apresenta valores elevados (até 0,75 ). Podemos logo, supor que, nesta zona várias espécies fitoplanctônicas cohabitam sem, todavia, encontrar condições. ecológicas ótimas; essas espécies muito diversificadas deverão despender um esforço que se traduz por um aumento dos teores em ATP (células de maior tamanho) e correlativamente, uma elevação da carga energética (David et al., 1977). 


\section{Sinecologia das Populą̧ōes Zooplanctônicas}

A dependência das populaçōes zooplanctônicas frente aos fatores do meio, parece ser menor que aquela do nível primário, pois com maior mobilidade que as células fitoplanctônicas, elas podem escapar às condições desfavoráveis (baixa salinidade, poluição) existindo nessas camadas superficiais, como testemunha a abundância 3 a 4 vezes maior dos organismos zooplanctônicos ao nível $-5 \mathrm{~m}$ em relação à superfície.

Porém' a sua repartição fica submetida às condiçð̃es hidrológicas. Nas áreas de diluiçẫo de produção primária muito elevada, - nível secundário é éssencialmente constituído por espécies oportunistas e resistentes, e de larvas diversas. São principalmente, herbívoros ou filtradores, cujo alimento compõe-se de algas fitoplanctônicas e đe material orgânico particulađo (Hillbricht-Ilkowska \& Weglenska, 1970). No interior destas comunidades, estavam representados os copépodos Acartia clausi e Paracalanus parvos, bem como - cladocero Podon polyphemoides, espécie de dominância herbívóra, cuja multiplicação está ligada ao nível de produção primária. As densidades mais elevadas são observadas fora das áreas de diluição, nas zonas de turbulência, em contáto com as águas marinhas. Assim, nestas zonas relativamente salgadas, os organismos zooplanctônicos não sofrem contaminação por poluentes já parcialmente degradados (Benon et al., 1977), podendo beneficiar o enriquecimento em algas fitoplanctônicas; além disso, as populações fitoplanctônicas, sendo mais maduras, correspondem melhor às exigências alimentares dos organismos zooplanctônicos (mais alta proporção de dinoflagelados). Nessas zonas, cadeias alimentares mais estruturadas estabelecem-se com a aparição dos carnívoros (quase ausentes nas áreas de diluição). Assim, podem manifestarem-se fenômenos de competição, sobretudo entre as espécies carnívoros (copépodos dos gêneros Corycaeus e Chaetog. natos do gênero Sagitta).

Ao nível bioquímico, diferenças na compoisção de proteínas e em algumas atividades esterásicas (lacticodesidrogenasas, citochromo-oxidase e esterases totais), podem ser postos em relevo para algumas espécies isoladas (Acartia clausi, Paracalanus parvus), bem como no conjunto da população (Benon et al., 1975a, b; Benon et al., 1977). Os organismos zooplanctônicos das zonas situadas na desembocadura de água doce, estão sujeitos às modificações, afetando o conjunto das populações: a atividade de alguns isozimos é inibida ainda que outras, em compensação, sâo estimuladas. $\mathrm{Em}$ alguns casos, quando o aporte de água doce apresenta altos teores em poluentes, essas variações enzimáticas são ainda mais importantes. Neste caso, a estrutura enzimafica reflete um estado fisiológico deficiente desses organismos.

\section{Conclusão}

As zonas de estuário são geralmente, áreas muito produtoras, eutróficas, pelo fato da imensa contribuição em sais nutrientes, base da cadeia alimentar dos rios. Hoje em dia, vários estuários são atingidos por esta poluição; cidades e complexos industriais são, com efeito, construidos nas suas proximidades. Além disso, os rios são várias vezes vetores de contaminação. Isso tem por conseqüência, o derramamento no mar de substâncias poluentes, podendo comprometer o equilíbrio do ecossistema estuarial, fazendo-o evoluir até um estado distrófico. Uma vigilância sistemática dessas zonas e uma análise dos diferentes parâmetros físicos, químicos e biológicos, deveriam ser feitos regularmente a fim de controlar as características hidrobiológicas deste meio ambiente.

\section{Bibliografia}

BENON, P.; BLANC, F.; BOURGADE, B.; KANTIN, R.; KERAMBRUM. P.: LEVEAU, M. \& SAUTRIOT, D. 1975a Essaj d'écotypologie proteique au niveau du sous-écosystème zooplanctonique d'une aire maritime polluée (Golfe de Fos). C.r. hebd. Séanc. Acad. Sci., Paris, sér. D, $281: 235-238$.

- $1975 b$ Note préliminaire sur un essai d'écotypologie protéique. Rapp. P. -v. Réun. Commn int. Explor. scient. Mer Méditerr., 23(3);67-68.

BENON, P.;BOURGADE, B. \& KANTIN, R. 1977. Impact de la pollution sur les écosystèmes méditerranéens côtiers: aspects planctoniques. Thèse Doctorat d'Etat. Université Aix-Marseille II.

BERLAND, B.; BONIN, D. \& MAESTRINI, S. 1974. Etude expérimentale de l'infuence des factuers nutritionnels sur la produc tıon du phytoplancton de Méditerranee. Thèse Doctorat d'Etat. Université Aix-Marseille II.

BLANC, F.; BLANC, J.J.; CAZABAT, C.; DEMATHIEW, P., LE VEAU, M.; ROUX, M. \& VERNIER, E. 1973. Interêt de la thermographie aérienne infra-rouge pour l'interprétation des phénomènes hydrologiques et sédimentologiques du Golfe de Fos. C. r. hebd. Séanc. Acad. Sci., Paris, 277 D: 561-564.

BLANC, F. \& LEVEAU, M. 1970a. Effects de l'eutrophie et de ta dessalure sur les populations phytoplanctoniques. Mar. Biol., 5(4): $283-293$

- \& - \& 1970b. Ecophysiologie des populations phytoplanctoniques dans les milieux eutrophes. Tethys, 2(2): 321-328.

BLANC, F. \& LEVEAU, M. 1973. Plancton et eutrophie: aire d'épandage rhôdanienne, Golfe de Fos (traitement mathématique des données). Thése Doctorat d'Etat. Université Aix-Marseille II. 681p.

- E \& BNIN, M. C. 1975a. Écosystème planc. tonique: structure et fonctionnement en relation avec des phénomènes de dystrophie, Golfe de Fos. Int. Revue ges. Hydrobiol., 60 (3): 359-378.

\& KERAMBRUN, P. 1975b. Eutrophie et. pollution: structure et fonctionnement du sous-écosystème planctonique. 10th European Symp. mar. B1ol., Ostend. Belgium, 2: 61-83.

BLANC, F.; LEVEAU, M. \& BONIN, M. C. 1976. Situation hydrologique du Golfe de Fos en 1969. Revue int. Oceanogr. méd.. 41/42:41-75

BOMSEL, J.L. \& PRADET, A. 1967. Étude des adénosines $5^{\prime}$ mono-, di- et tri-phosphates dans les tissus végétauxII Evolution in vivo de 1'ATP, de 1'ADP, et de 1'AMP dans les feuilles de blé, en fonction de différentes conditions du milieu. Phy siol. vég., 5:223-236.

BRUCE, H. E. 1969. The role of dissolved amino-acids as a nitrogen source for marine phytoplankton in an estuarine environment in Southeastern Alaska. Ph. D. Thesis. Corvallis, Oregon State University.

CARLUCCI, A.F.; HARTWIG, E. O. \& BOWES, P. M. 1970. Biological production of nitrites in sea-water. Mar. Biol. $7(2): 161-166$

CARPENTER, J. H. ; PRITCHARD, D. W. \& WHALEY, R. C. 1969 Observation of eutrophication and nutrient cycles in some coastal plain estuaries. In: Eutrophication: causes, consequences, correctives. Washington, D.C., Nat. Acad. Sci. p. $210-221$.

DAVID, P.; ROMANO, J. C.; SAUTRIOT, D.; BENON, P.; BOURGADE, B.; KANTIN, R. \& LEVEAU, M. 1977. Impact de la pollution sur un écosystème côtier: relation entre la composition spécifique des populations phytoplanctoniques, le taux de pigments et les nucléotides adényliques (ATP. ADP, AMP). Int. Revue ges. Hydrobiol., 62 (5):631-648.

HARGANE, B. T. \& QUEEN, G. H. 1968. Phosphorus excretion by zooplankton. Limnol. Oceanogr., 13:332-335.

HILLBRICHT-ILKOWSKA A. \& WEGLENSKA. T. 1970. Some relations between production and zooplankton structure in two lakes of a varying trophy. Polskie Archwn Hydrobiol. $17(1 / 2): 133-140$

LORENZEN, C. J. 1967. Vertical distribution of chlorophyll and phaeopigments: Baja California. Deep Sea Res., 14: 735-745.

LUND, J. W. G. 1969. Phy toplankton. In: Eutrophication: causes, consequences, correctives. Washington, D. C., Nat. Acad. Sci. p.306-330.

McCARTHY, J. J. 1972. The uptake of urea by marine phytoplankton, J. Phycol, $8: 216-222$.

PETERS, B. H. 1975. Phosphorus excretion and the measurement of feeding and assimilation by zooplankton. Limnol. Oceanogr., 20 (5): $858-859$

POMEROY, L. R.; MATHEWS, H. M.\&MIN, H. S. 1963. Excretion of phospháte and soluble organic phosphorus compounds by zooplankton. Limnol Oceanogr., 8: 50-65.

PRADET, A.; NARAYANAN, A. \& VERMERSCH, I. 1968. Etude des adénosines 5 ' mono-, di- et triphosphates dans les tissus végétaux. III. Métabolisme énergétique aux cours des premiers stades de la germination des semences de laitue. Bull. Soc. fr. Phýsiol. vég., 14:107-114.

PROVASOLI, L. 1969. Algal nutrition and eutrophication. In: Eutrophication: causes, consequences, correctives. Washington, D.C., Nat. Acad. sci., p. 574-593.

ROMANO, J. C. 1975. Les adénosines 5 ' phosphate chez les algues planctoniques en culture et en zone eutrophe (Golfe de Fos) 
Signification métabolique et ecologique. Thése Doctorat d'Etat. Université Aix-Marseilles II.

RYTHER, J. H. 1954. The ecology of phytoplankton blooms in Morisches Bay and Great South Bay, Long Island, New York. Biol. Bull mar, biol. Lab. Woods Hole, 106:198-209.

SEIWELL, A. R. \& SEIWELL, G. E. 1938. The sinking of decomposing planktón in sea water and its relationship to oxygen con- sumption ana pnosphorus liberation. Proc. Am. Ynil. Soc. $78(3)$.

SLOAN, P. R. \& STRICKLAND, J. D. H. 1966. Heterotrophy of four marine phytoplankters at low subştrate concentrations. J. Phycol, 2:17-23.

SOURNIA, A. 1970. Les cyanophycées dans le plancton marin. Ann. Biol., $9(1 / 2): 63-76$. 